\title{
Tecnologias digitais e formação de professores: Percepções e Relatos de Experiências de Alunos de um Curso de Especialização em Informática na Educação
}

\author{
Ana Gardenia Lima Martins Mendes -Universidade do Minho - \\ anagardenia_lm@hotmail.com
}
João Batista Bottentuit Junior Universidade Federal do Maranhão - UFMA joaobbj@gmail.com

Resumo: Este estudo apresenta a inclusão de recursos e metodologias possibilitadas pelas tecnologias digitais por meio das práticas dos alunos de um curso de formação continuada, além disto, utilizou-se das suas próprias percepções sobre o curso ofertado na modalidade a distância. Trata-se de um estudo de caso exploratório - descritivo qualiquantitativo, realizado com 70 alunos do curso de Especialização em Informática na Educação do Instituto Federal do Maranhão. Os dados da pesquisa foram obtidos através de questionários elaborados no Google Forms, e os resultados demonstram que o curso apresenta-se como um importante meio para auxiliar seus alunos, enquanto professores, a integrar as tecnologias digitais em suas salas de aula. E, por ser na modalidade a distância, colabora com ferramentas e metodologias ao inserir seus próprios alunos na educação virtual.

Palavras-chave: Tecnologias Digitais, Formação de Professores, Relatos de Experiências.

\section{Digital Technologies and Teacher Training: \\ Perceptions and Reports of Experiences of Students of the Specialization course in Informatics in Education}

\begin{abstract}
This study presents the inclusion of resources and methodologies made possible by digital technologies through the students' practices of a continuing education course, besides their own perceptions about the course offered in the distance modality. This is an exploratory case study - descriptive qualitative and quantitative, conducted with 70 students of the Specialization Course in Informatics in Education of the Federal Institute of Maranhão. The results were obtained through questionnaires prepared in Google Forms, and demonstrate that the course is an important way to help their students, as teachers, to integrate digital technologies in their classrooms. And, being in the distance mode, collaborates with tools and methodologies to insert their own students in virtual education.
\end{abstract}

Keywords: Digital Technologies, Teacher Training, Reports of Experiences.

\section{Introdução}

A expansão das Tecnologias da Informação e Comunicação (TIC) vem acompanhada de exigências, seja por questões de conhecimento, inclusão, adaptação ou formas de potencialização, no intuito de atender e possibilitar o uso consciente e condizente da cultura que se difunde e se produz em torno delas. No contexto educacional, sabe-se da necessidade de se manter numa vivência dessa constante linha de atualização, ou seja, é importante que os professores compreendam os elementos e se V. $17 \mathrm{~N}^{\circ}$ 3, dezembro, 2019 RENOTE DOI: 
apropriem das dinâmicas que regem a sociedade e, por conseguinte, se refletem em seu cotidiano escolar (VIEIRA \& RESTIVO, 2014; MENDES, 2015; MORAN, MASETO \& BEHRENS, 2015).

A formação continuada busca essa conectividade entre os profissionais e seu meio, visto que sua proposta é aperfeiçoar, atualizar e ampliar. Nesse sentido, pode se considerar que a formação continuada é a principal ferramenta para que os professores possam superar os desafios advindos dessas transformações, possam ainda se integrar e obter conhecimentos que os capacitem a reconhecer os suportes pedagógicos que se apresentam na realidade atual. Apesar das relevantes e necessárias perspectivas que se delineiam por meio da formação continuada, alguns problemas ainda dificultam tanto o acesso quanto à apropriação do seu propósito (SACRISTAN, 1999; NÓVOA, 2009; IMBERNOM, 2010).

Como aluna de uma das turmas do Curso de Especialização em Informática na Educação do Instituto Federal do Maranhão (IFMA), partiu o interesse de verificar junto aos demais alunos, como o curso estaria auxiliando-os a integrar as tecnologias digitais em sala de aula, e como o uso das próprias tecnologias, por meio da Educação a Distância (EaD), tem ajudado a facilitar a formação continuada. Em termos específicos, o objetivo deste estudo é conhecer, na perspectiva dos alunos, que também são professores, a ampliação do conhecimento sobre as TIC e sua inclusão nas práticas pedagógicas possibilitadas pelo curso de Especialização em Informática da Educação do IFMA, além de demonstrar algumas experiências realizadas através desse conhecimento, identificando ainda as dificuldades ou falhas verificadas durante a implementação do curso.

Para o alcance desses objetivos utilizou-se como procedimento metodológico, uma pesquisa quali-quantitativa através de um questionário, aplicado via Google Forms, a 70 alunos das turmas do curso de Especialização em Informática da Educação do IFMA do polo de São Luís. Os resultados que serão demonstrados visam promover melhorias na própria implementação do curso, assim como, verificar como o conhecimento teórico apreendido pode ser colocado em prática, além de observar os benefícios que um curso relacionado às tecnologias digitais na educação pode viabilizar as condições para uma construção permanente e alinhada ao cenário de uma sociedade informatizada.

O roteiro que estrutura este trabalho é constituído por esta seção introdutória e mais três outras seções. A fundamentação teórica destaca os estudos sobre tecnologias digitais e a formação continuada de professores, e na metodologia apresenta-se o campo de pesquisa. Resultados e discussões, que compreende a pesquisa realizada com alunos do curso de Informática na Educação do IFMA. A última seção contempla as considerações finais, relacionando o que foi proposto com o que foi alcançado.

\section{Tecnologias Digitais e Formação Continuada De Professores}

O debate sobre o uso das tecnologias digitais na educação e as dificuldades sobre sua inserção, principalmente no que diz respeito à preparação do professor, apesar de já muito discutido, é uma pauta que se deve persistir, e de forma incansável buscar meios para atender, de modo significativo, as demandas pertinentes.

As TIC possibilitam novos construtos para o processo de ensino e aprendizagem, pois auxiliam na passagem de modelo de reprodução da informação para um modelo de produção, fundamentado na construção colaborativa de conhecimentos, refletido nos contextos culturais e sociais, na diversidade dos alunos, em suas experimentações e interesses, podendo constituir-se como uma verdadeira comunidade 
de aprendizagem (MENDES, 2015, p.16). As benesses advindas pelo uso das TIC no processo pedagógico são infinitas, mas também desafiadoras, tanto para algumas instituições quanto para os educadores. Superar as práticas tradicionais e garantir um ensino de qualidade é um desafio para todos, principalmente para aqueles que lidam diretamente com os alunos - os professores. Muitas são as dificuldades, sobretudo, para aqueles que trabalham em escolas com uma realidade problemática, que possuem poucos recursos, mas que precisam desenvolver suas atividades e suplantar o fracasso escolar. Por outro lado, as práticas pedagógicas têm sido auxiliadas pelo avanço tecnológico, propiciando maior poder de troca de informações e experiências que podem ser adotadas ainda em espaços pouco estruturados.

O envolvimento do docente com as TIC pode servir como meio para auxiliar sua própria formação em diversas áreas do conhecimento, como é o caso da Educação a distância, e/ou ainda como objeto de conteúdo complementar ao processo pedagógico. A EaD tem auxiliado bastante a formação de professores, e "se antes vista como uma modalidade secundária, atualmente é uma opção cada vez mais importante para aprender ao longo da vida, para a formação continuada" (MORAN, MASETO e BEHRENS, 2015, p. 63). Não cabe aqui apontar as inúmeras vantagens da EaD, mas, é preciso reconhecer que seu avanço mediante as tecnologias digitais tem sido fundamental para o alcance de um público praticamente inacessível, seja por questões de localização, tempo ou custo. E, a questão da informática na educação deve ser considerada porque, ainda que algumas escolas não sejam abastecidas por esses recursos, os professores estão cientes de que fora das escolas, esses artefatos tecnológicos fazem parte do cotidiano dos seus alunos.

Neste mote, o curso de Especialização em Informática da Educação do IFMA compreende essas duas linhas, visto que é ofertado na modalidade a distância e, desse modo já se configura por meio das TIC, assim como, tem como escopo do seu programa curricular a Informática na Educação e seus desdobramentos.

\section{Metodologia}

Considerando a abordagem e o método adequados para melhor atender este trabalho optou-se pelo estudo de caso exploratório - descritivo de abordagem quantitativa com breve apreciação qualitativa. Como leciona Gil (2018), a pesquisa Exploratória - descritiva tem por finalidade descrever particularidades ou fenômenos de um público específico, possibilitando maior familiaridade com o problema.

Esse tipo de pesquisa é interessante, pois após a obtenção e registros de dados e informações, estes podem ser comparados ao longo do tempo, permitindo traçar um histórico das informações e assim dar continuidade, rever falhas e/ou promover melhorias pertinentes ao assunto tratado.

\subsection{Campo de pesquisa}

O curso de Especialização em Informática da Educação é gratuito, na modalidade a distância da Universidade Aberta do Brasil (UAB), oferecido pelo Centro de Referência em Tecnologia (CERTEC) do IFMA. Esta pesquisa contempla um estudo realizado com um total de 70 estudantes do Curso de Especialização em Informática na Educação do IFMA, das turmas de São Luís, ofertadas nos anos de 2017 e 2018 .

\section{Resultados e Discussões}

V. $17 \mathrm{~N}^{\mathrm{o}}$ 3, dezembro, 2019

DOI: 
As informações apresentadas foram obtidas através de questionários elaborados no Google Forms, contendo 12 questões, sendo 10 objetivas e duas subjetivas. A coleta foi realizada entre os meses de janeiro e março de 2019. Toda a discussão é fundamentada e comentada através de estudos pertinentes e são demonstrados graficamente, a seguir.

As Figuras de 1 a 5 apresentam informações sobre os próprios alunos, seus conhecimentos e práticas a partir do curso. Enquanto as demais questões buscam conhecer suas percepções a respeito do curso. Para iniciar, considerou-se interessante questionar sobre os conhecimentos prévios dos alunos em relação à área de estudo do curso, no intuito de conhecer as bases e possíveis perspectivas diante da procura por esta formação. Como demonstra a Figura 1, a seguir.

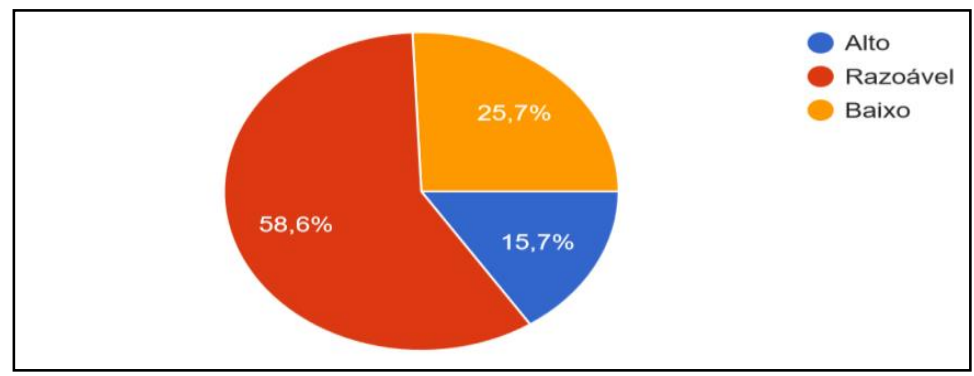

Figura 1: Grau de conhecimento prévio sobre os conteúdos abordados no curso.

De acordo com a Figura 1, a maioria, $41(58,6 \%)$ dos alunos, afirmou ter um conhecimento intermediário/razoável, enquanto $18(25,7 \%)$ dos alunos, responderam ter um conhecimento prévio baixo, e apenas $15(15,7 \%)$ dos alunos afirmaram já possuir bastante conhecimento sobre os conteúdos abordados ao longo do curso.

Estas respostas vêm corroborar com a importância da formação continuada de professores. Apesar da maioria dos sujeitos apresentar um conhecimento prévio intermediário, e inferindo-se que as TIC fazem parte do cotidiano, de modo geral, para que o uso das TIC signifique uma transformação educativa, muitas coisas terão que mudar. "Os próprios professores terão que redesenhar seus papéis e suas responsabilidades na escola atual" (IMBÉRNOM, 2010, p.3). Nessa perspectiva, os professores precisam de uma constante atualização da sua formação. Trazendo para a realidade do curso de Especialização em Informática na Educação do IFMA, por ser ofertado na modalidade a distância, já insere os alunos diretamente ao convívio com os recursos digitais, exigindo deles maior frequência de uso dessas tecnologias em seu aprendizado, ao mesmo tempo, que vai enquadrando esse uso às possibilidades de aplicação em sala de aula presencial.

Objetivando verificar as possibilidades de aplicação da informática na educação, questionou-se aos alunos se estavam atuando como professor durante o período de formação do curso, em destaque na Figura 2.

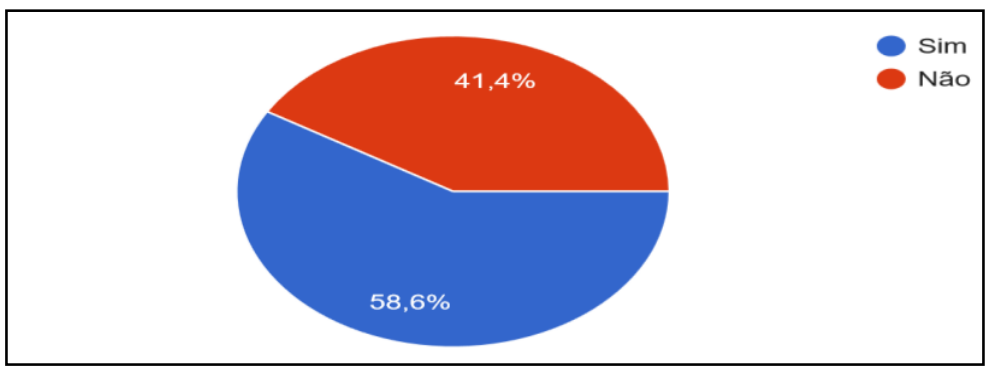

Figura 2: Atuando como professor.

Conforme demonstra a Figura 2, do total de 70 alunos, cerca de 41(58,6\%) dos V. $17 \mathrm{~N}^{\circ}$ 3, dezembro, 2019 DOI: 
alunos confirmaram estar atuando como professor, e $29(41,4 \%)$ não estão atuando como professor.

Verificando sobre a aplicação dos conteúdos apreendidos durante o curso, a Figura 3 demonstra os seguintes resultados.

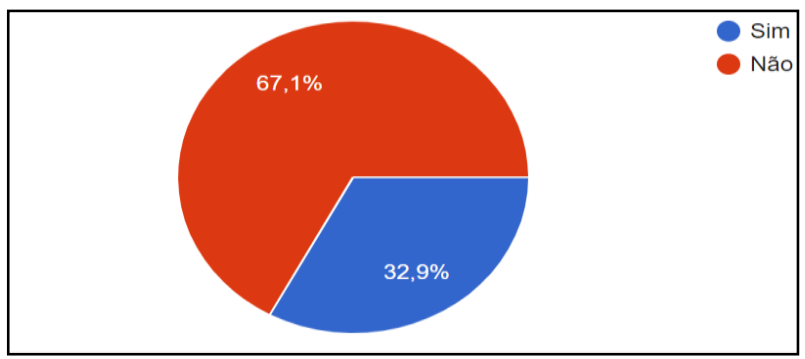

Figura 3: Aplicação de atividade a partir do aprendizado obtido no Curso.

Obteve-se a afirmação de que 23 (32,9\%) participantes trabalharam a informática na educação. Comparando com os dados da Figura 2, em que 41 participantes confirmaram estar atuando como professor, pode se afirmar que 18 participantes, que estão atuando como professor, não aplicaram atividades que contemplam os conteúdos abordados no curso. Desse modo, mais da metade, 47 $(67,14 \%)$ dos alunos do curso, atuando ou não como professor, afirmou não ter aplicado atividades utilizando elementos da informática. "Educação e Tecnologia caminham juntas, mas unir as duas é uma tarefa que exige preparo do professor, ao mesmo tempo em que oferece desafios e oportunidades, o ambiente digital pode tornar-se um empecilho para o aprendizado quando mal usado" (NEIRA, 2016, p. 4).

Complementando as respostas acima, também se questionou quais experiências foram realizadas e quais disciplinas do curso as fundamentaram. Dos 23 alunos/professores, 22 responderam e os resultados são apresentados na Tabela 1:

Tabela 1: Relatos de experiências a partir do aprendizado no curso.

\begin{tabular}{|c|c|}
\hline $\begin{array}{c}\text { ATIVIDADES } \\
\text { (Recursos, estratégias, metodologias) } \\
\end{array}$ & $\begin{array}{l}\text { DISCIPLINAS DO CURSO QUE } \\
\text { FUNDAMIENTARAM A ATIVIDADE } \\
\end{array}$ \\
\hline Jogos e vídeos na Educação Infantil & Sistemas Multimídia \\
\hline Gravação de vídeo apresentado em seminário & $\begin{array}{llll}\text { Recursos } & \text { audiovisuais } & \text { e } & \text { Sistemas } \\
\text { Multimídia } & & & \\
\end{array}$ \\
\hline Minicurso sobre uso das TICs. & Não informado \\
\hline $\begin{array}{l}\text { Trabalhou com Realidade Aumentada, Mapa de palavras, } \\
\text { com Mobile learning, tablet e computador. }\end{array}$ & Não informado \\
\hline Utilizou recursos multimídias. & Não informado \\
\hline Fez uso de equipamentos multimídias. & Sistemas Multimídia \\
\hline $\begin{array}{l}\text { Produção de vídeos educativos; software para leitura e } \\
\text { escrita; e HQs do repositório da disciplina. }\end{array}$ & $\begin{array}{l}\text { Softwares educacionais e Objetos de } \\
\text { aprendizagem }\end{array}$ \\
\hline Trabalhou com ferramentas web no ensino de geometria. & Não informado \\
\hline Uso do aplicativo Plickers e LD. & Não informado \\
\hline $\begin{array}{l}\text { Uso de um editor de textos para trabalhar o gênero textual } \\
\text { de receitas culinárias. }\end{array}$ & $\begin{array}{l}\text { Softwares educacionais e Objetos de } \\
\text { aprendizagem }\end{array}$ \\
\hline Uso de app para medição de temperatura e Google Maps. & Não informado \\
\hline Produção de vídeos educativos. & Não informado \\
\hline Utilização de vídeos e slides. & $\begin{array}{l}\text { Sistemas } \quad \text { Multimídia; } \\
\text { educacionais e }\end{array}$ \\
\hline $\begin{array}{l}\text { Aplicativo de medição de temperatura, Google Maps e } \\
\text { Excell. }\end{array}$ & $\begin{array}{llll}\text { Recursos } & \text { audiovisuais } & \text { e } & \text { Sistemas } \\
\text { Multimídia } & & & \\
\end{array}$ \\
\hline Utilização de vídeos e slides & O curso em geral \\
\hline Recursos audiovisuais (vídeos, data-show e notebook) & Recursos audiovisuais \\
\hline Aplicação da metodologia da Sala de Aula Invertida & Não informado \\
\hline Facebook e WhatsApp nas aulas de matemática. & Não informado \\
\hline
\end{tabular}

V. $17 \mathrm{~N}^{\circ} 3$, dezembro, 2019

DOI: 


\begin{tabular}{|l|c|}
\multicolumn{1}{c}{ ATIVIDADES } & DISCIPLINAS DO CURSO QUE \\
\multicolumn{1}{c|}{ Recursos, estratégias, metodologias) } & FUNDAMENTARAM A ATIVIDADE \\
\hline Metodologias que envolvem multimídias. & Não informado \\
\hline Uso de equipamentos multimídia e redes sociais. & Todas as disciplinas \\
\hline Recursos de multimídia. & Não informado \\
\hline Informática básica (noções de Word, Excel...) & Não informado \\
\hline
\end{tabular}

Fonte: Os próprios autores (2019)

Conhecer as atividades que foram trabalhadas e reconhecer que o curso incentivou o uso das tecnologias em sala de aula permite observar os reflexos pertinentes ao propósito da formação continuada. Além disso, sabe-se que a inserção das TICs na educação favorece o ensino de qualidade (AGUIAR e NASCIMENTO, 2014).

Ampliando o questionamento sobre a aplicação de atividades a todos os participantes, questionou-se sobre como se sentiam em relação às suas habilidades para trabalhá-las. E, conforme demonstra a Figura 4, a maioria (95\%) respondeu se sentir capacitado a aplicar os conhecimentos adquiridos.

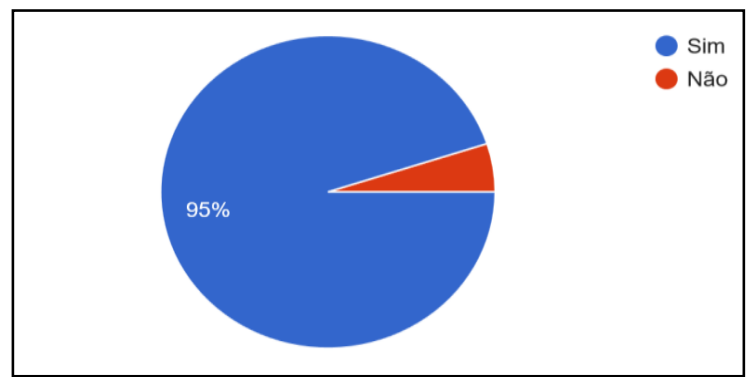

Figura 4: Capacitado para aplicar os conhecimentos adquiridos durante o curso.

Em atenção tanto aos resultados apresentados na Tabela 1 quanto na Figura 4, é preciso observar que o uso das TIC em sala de aula demanda mais do que conhecimento técnico, demanda também conhecimento pedagógico, metodológico e social. Para que os professores possam exercer o ato de ensinar, utilizando as TIC há que se ter formação ancorada nesses conhecimentos (ZAIONS e MOREIRA, 2016).

Mais uma vez incorre neste ponto, a questão da importância dos cursos de formação continuada, pois a preocupação não é apenas inserir recursos tecnológicos no cotidiano escolar, é tornar seu uso realmente significativo no processo educativo.

Direcionando a análise para o olhar avaliativo dos alunos sobre o curso (Programa, Material Didático, Curso em geral, e Conteúdos significativos), os resultados são apresentados nas Figuras 5, 6, 7 e 8, respectivamente.

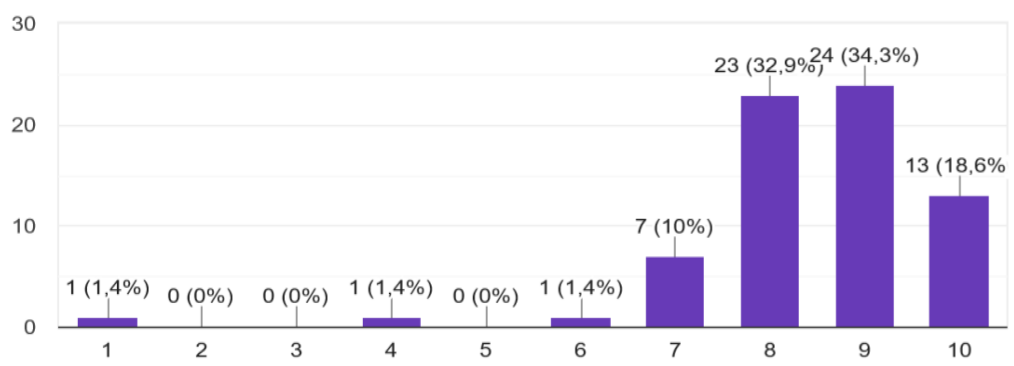

Figura 5: Avaliação do Programa do Curso.

Como destaca a Figura 5, apenas $3(4,28 \%)$ deram nota inferior a 7 em relação ao Programa do Curso. Significativamente, o restante, totalizando 67 (95,71\%), avaliou positivamente, com notas variando entre razoável e muito bom. Em geral os mentores e implementadores de programas ou cursos de formação continuada, que visam a mudanças em cognições e práticas, têm a concepção de que, oferecendo informações, V. $17 \mathrm{~N}^{\circ}$ 3, dezembro, 2019 RENOTE DOI: 
conteúdos, trabalhando a racionalidade dos profissionais, produzirão a partir do domínio de novos conhecimentos mudanças em posturas e formas de agir (GATTI, 2003). Para a autora, diante das necessárias mudanças sobre as concepções e práticas educacionais, é imprescindível focar nas dificuldades advindas dessas mudanças.

Como se pode observar, esse resultado sobre o programa do curso é muito interessante, pois revela uma percepção positiva, compreendendo que diante disso, o programa do curso atendeu as expectativas dos alunos.

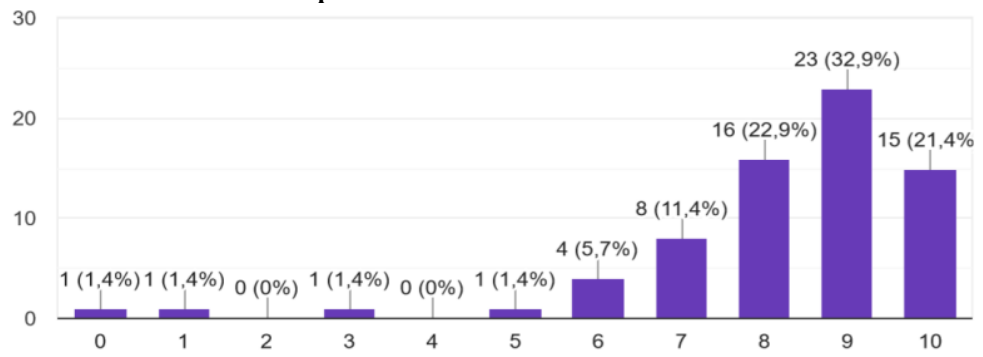

Figura 6: Avaliação do Material didático.

No que diz respeito ao Material didático, os índices já apresentam maior insatisfação, pois $8(11,42 \%)$ alunos avaliaram esse recurso com notas entre 0 e 6 . No entanto, a maioria, $62(88,57 \%)$ avaliou de modo positivo, variando as notas entre 7 e 10.

De acordo com os Referenciais de qualidade para a Educação Superior a Distância, o Material Didático, tanto do ponto de vista da abordagem do conteúdo, quanto da forma, deve estar concebido de acordo com os princípios epistemológicos, metodológicos e políticos explicitados no projeto pedagógico, "de modo a facilitar a construção do conhecimento e mediar a interlocução entre estudante e professor, devendo passar por rigoroso processo de avaliação prévia, com o objetivo de identificar necessidades de ajustes, visando o seu aperfeiçoamento" (BRASIL, 2007, p.13).

$\mathrm{O}$ curso disponibilizou materiais e informativos demonstrando o alinhamento do material didático ao programa do curso e aos referenciais de qualidade, e de acordo com o resultado demonstrado pela maioria dos alunos, isso foi positivo.

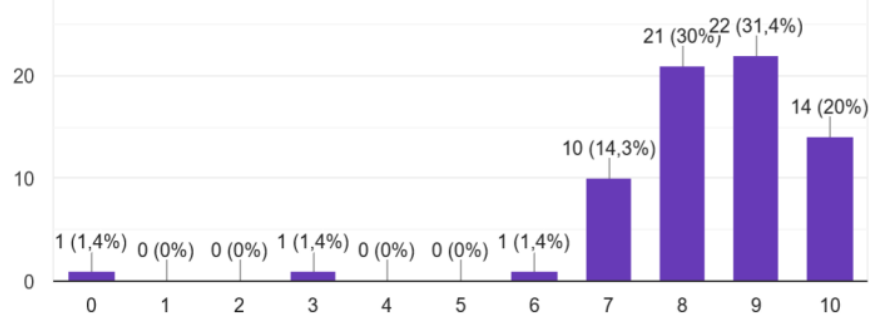

Figura 7: Avaliação do Curso.

Sobre o curso em geral, a Figura 7 revela que a avaliação foi muito positiva. Apenas $3(4,28 \%)$ deram nota inferior a 7, enquanto a maioria avaliou entre 7 e 10.

A educação a distância $(\mathrm{EaD})$ é recurso importante para a socialização ampliada de formações, mas, é muito exigente quanto a suas características no que se refere à qualidade da forma de oferta. "Essa modalidade formativa engloba novas perspectivas formativas e diferenciais de comunicação" (GATTI, 2015, p. 11).

Constatar essa satisfação com o curso de Especialização em Informática na Educação do IFMA é muito importante, não só pelo foco nas tecnologias, mas pela sua própria oferta na modalidade a distância, pois a $\mathrm{EaD}$ tem lutado e buscado não só pela expansão, mas, sobretudo, pela qualidade. 


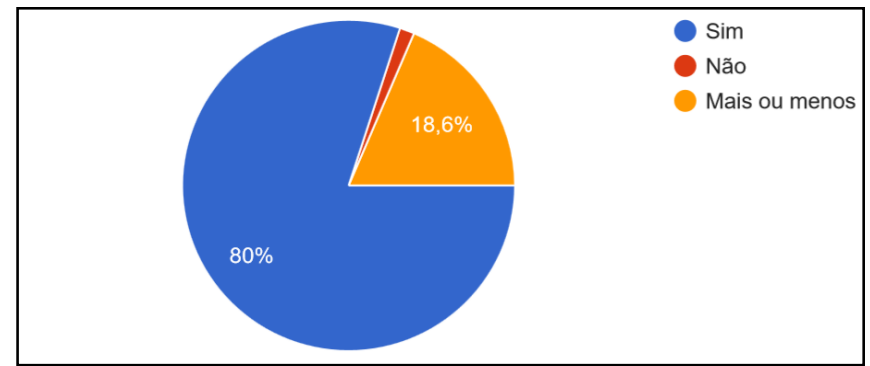

Figura 8: Conteúdos significativos para o cotidiano profissional.

Corroborando a avaliação positiva sobre o curso, na Figura 8, a maioria, 56 (80\%) alunos, considera que os conteúdos abordados no curso são significativos para o cotidiano profissional. Apenas $1(1,4 \%)$ aluno informou não considerar o conteúdo significativo, e $13(18,6 \%)$ consideraram razoável.

Reunindo as informações obtidas nas Figuras de 6 a 8 , há que se atentar que a $\mathrm{EaD}$, apresenta-se "numa dinamicidade própria e complexa, e os detalhamentos para a sua efetiva qualidade exigem respostas aos termos normativos construídos" (PASCHOALINO et al, 2015, p. 18) pois, além de enfrentar os mesmos problemas identificados na educação presencial, ainda se acrescenta à EaD dificuldades relacionadas a: "conteúdos corretos e atualizados, professores qualificados, tutores qualificados, atendimento ágil às necessidades dos alunos, metodologias eficazes e gestão eficaz" (CENSOEAD.BR, 2018, p. 35).

A última pergunta do questionário buscava informações sobre o que faltou ou foi desnecessário, sugestões, reclamações e elogios. Na Tabela 2 a seguir, as respostas são apresentadas por ano de oferta do curso:

TABELA 2: Reclamações, sugestões e elogios sobre o Curso.

\section{RECLAMAÇÕES E SUGESTÕES}

Deveria ter mais encontros presenciais.

Deveria ter mais seminários.

Faltou laboratório para utilização dos recursos.

As disciplinas deviam ter atividades práticas.

O curso foi muito teórico.

Faltou a disponibilização de uma biblioteca.

Nem todas as disciplinas tiveram revisão.

A revisão das disciplinas é desnecessária.

Falta melhorar a didática do tutor.

Faltou um questionário deste no início do curso.

Apostilas desatualizadas.

Melhor seleção de alguns vídeos.

Faltou mais Chat.

Demora de orientadores para o TCC.

Problemas/instabilidades com o AVA.

Faltou melhor organização do curso.

Extensão do curso além dos 18 meses.

Falta de tempo pra estudar, desisti do curso.
As aulas presenciais deveriam ser mais efetivas.

ङ Deveria ter mais seminários.

Faltaram aulas práticas para uso dos recursos.

As disciplinas deviam ter atividades práticas.

As avaliações são muito conteudistas.

Melhor localização para as aulas presenciais.

Faltou maior aprofundamento na abertura das disciplinas.

Faltou professores mais qualificados.

Tutoria inflexível e pouco acompanhamento. Faltou workshop.

Apostilas desatualizadas.

Conteúdos repetitivos nas disciplinas

Ambientação em EaD e História da Informática

Educativa.

Fóruns não avaliativos são desnecessários.

Todos os materiais deviam ser impressos.

Faltou incluir a disciplina Inteligência Artificial e outros importantes conteúdos da Informática.

Demora de orientadores para o TCC.

Problemas/instabilidades com o AVA.

of Falta tudo no curso.

Alterações no calendário do curso prejudicam o planejamento do aluno.

Faltou feedback e flexibilidade da coordenação.

As provas de repercurso deviam ser online. RENOTE

V. $17 \mathrm{~N}^{\mathrm{o}}$ 3, dezembro, 2019

DOI: 
ELOGIOS

\begin{tabular}{|l|l|}
\hline \hline Tudo foi muito bem trabalhado. & Não faltou nada, tudo foi muito bem realizado. \\
\hline O curso foi excelente. & Toda a didática do curso foi muito significativa. \\
\hline & Houve compromisso da coordenação em geral. \\
\hline
\end{tabular}

Fonte: Os próprios autores (2019)

Diante do exposto na Tabela, é possível perceber alguns contrapontos na Turma de 2017, houve quem considerasse importante a revisão ao final das disciplinas, enquanto outro apontou ser desnecessário. Mas, em percepções gerais, as duas turmas destacaram: sobre a importância dos encontros presenciais; a necessidade de aulas práticas; reclamações em relação aos materiais didáticos; a instabilidade do Ambiente Virtual de Aprendizagem (AVA); e, sobre a demora na apresentação dos orientadores do Trabalho de Conclusão de Curso (TCC). No que se refere aos elogios, houve quem considerasse o curso ter se desenvolvido de forma excelente, muito bem organizado, e coordenação comprometida.

\section{Considerações Finais}

A partir dos resultados obtidos neste estudo, foi possível confirmar que os objetivos propostos na pesquisa foram alcançados, visto que o Curso de Especialização em Informática na Educação, como um curso de formação continuada, demonstra-se como importante meio para auxiliar professores a integrar as tecnologias digitais em sala de aula e, por ser na modalidade a distância, por si só, colabora com ferramentas e metodologias a inserir os seus alunos nesse mundo da educação virtual.

Conhecer as percepções dos alunos sobre o curso de formação continuada ao qual estão inseridos e verificar quais os reflexos do auxílio das tecnologias tanto na sua formação quanto nas suas práticas pedagógicas permite ter uma visualização das ações e das relações aluno-professor, aluno/professor diante das novas possibilidades $\mathrm{e}$ exigências do seu contexto, pois como afirma Imbernon (2010) não se pode falar nem propor alternativas à formação continuada sem antes analisar o contexto político-social como elemento imprescindível na formação.

A maioria dos respondentes, ainda que não tenham aplicado na prática os conhecimentos apreendidos durante o curso, afirmaram se sentir capacitados para aplicá-los, possibilitando um olhar autoavaliativo. Também foi possível conhecer as atividades aplicadas por esses alunos/professores em suas respectivas salas de aula. Além disso, as informações avaliativas sobre programa do curso, material didático, conteúdos significativos, e do próprio curso em geral, assim como, as reclamações, sugestões e elogios permitem que o curso possa apreciar possíveis alterações, inclusões e melhorias, dar continuidade aos pontos observados como positivos. De acordo com Casanova (2013) a formação de professores só tem sentido se for capaz de estar ao serviço da satisfação das necessidades dos alunos, dos professores, das instituições e da comunidade educativa, sendo capaz de exercer uma ação transformadora nos diversos aspectos de desenvolvimento dos sujeitos envolvidos.

Por fim, considera-se que apesar da objetividade, as informações apresentadas foram substanciais para agregar e demonstrar a importância do curso, além de fornecer informações para a sua melhoria frente as necessidades do atual cenário educacional.

\section{Referências}

AGUIAR, M. O.; NASCIMENTO, E.L do. Tecnologia a favor da Educação: Um Estudo de Caso das Escolas do Espírito Santo. $3^{\circ}$ Congresso Brasileiro de 
Informática na Educação e 20ª Workshop de Informática na Escola, 2014.

BRASIL. Ministério da Educação - MEC. Referências de qualidade para a Educação Superior a Distância. Brasília, DF: Secretaria de Educação a Distância, 2007.

CASANOVA, M.P. Avaliação da Formação Contínua de Professores. In Teresa Estrela et al. Formação Profissional: Investigação Educacional sobre teorias, políticas e práticas. Lisboa: EDUCA/Secção Portuguesa da AFIRSE, 2013.

CENSO EAD.BR. Relatório analítico da aprendizagem a distância no Brasil 2017. [Org.] ABED - Associação Brasileira de Educação a Distância; [trad.] Maria Thereza Moss de Abreu. Curitiba: InterSaberes, 2018.

GATTI, B. A. Formação continuada de professores: a questão psicossocial. Cadernos de Pesquisa, São Paulo, n.119, p.191-204, 2003. Disponível em http://www.scielo.br/pdf/cp/n119/n119a10.pdf/. Acesso em 20 abr 2019.

Formação de professores: licenciaturas, currículos e políticas. Movimento Revista de Educação, ano 2, n. 2, Universidade Federal Fluminense, 2015. Disponível em: periodicos.uff.br/revistamovimento_teste/article /download/20879/12354. Acesso em 14 abr 2019.

IMBERNÓN, F. Formação docente e profissional: formar-se para a mudança e a incerteza. 7. Ed. São Paulo: Cortez, 2010.

MENDES, A. G. L. M. Estilos de aprendizagem no espaço virtual: um estudo com alunos dos cursos a distância da Universidade Federal do Maranhão - UFMA. Dissertação (Mestrado em Cultura e Sociedade) - São Luís, 2015.

MORAN, J.M.; MASETTO, M.T.; BEHRENS, M.A. Novas tecnologias e mediação pedagógica. Campinas: Papirus, 2015.

NEIRA, A. C. Professores aprendem com a tecnologia e inovam suas aulas. Jornal Estado de São Paulo. 24 de fevereiro de 2016. São Paulo, 2016.

NÓVOA, A. Para uma formação de professores construída dentro da profissão. In Professores: imagens do futuro presente (pp. 25-46). Lisboa: Educa, 2009.

PASCHOALINO, J. B. Q; NEVES, I.S.V.; CAMPOS, F. A. C.; FIDALGO, F. S. R. EaD entre os ditames legais e a realidade concreta. Revista Brasileira de Informática na Educação, Volume 23, Número 1, 2015.

SACRISTÁN, J.G. Poderes instáveis em educação. Porto Alegre: Artmed, 1999.

SILVA, EM. Formação continuada e as novas tecnologias da informação e comunicação. In: SOUSA, RP., et al., orgs. Teorias e práticas em tecnologias educacionais. Campina Grande: EDUEPB, 2016, pp. 7-15.

VIEIRA, F; RESTIVO, M. T. Novas Tecnologias e Educação: Ensinar a Aprender, Aprender a Ensinar. Biblioteca Digital da Faculdade de Letras da Universidade do Porto Ano de edição: 2014.

ZAIONZ, R. e MOREIRA, H. Formação continuada de professores e os desafios das novas tecnologias. REDIVI - Revista de Divulgação Interdisciplinar Virtual do Núcleo das Licenciaturas, Volume 4, número 1. UniVali, 2016. 